\title{
The Greenwich Maths Arcade: A Tool For Nurturing The Inquiring Mind
}

\author{
Noel-Ann Bradshaw and Steve Lakin \\ University of Greenwich, School of Computing \& Mathematical Sciences
}

\begin{abstract}
The Greenwich Maths Arcade, which provides support and enrichment for mathematics students and opportunities for students to interact with members of staff, was introduced in 2010 and has been expanded in 2011-12. It has been well received by students and statistics show improved retention and student achievement. Following the authors' presentation at the university's Learning and Teaching conference and papers at national conferences, similar initiatives are being introduced in the University of Greenwich's Business School and by a number of maths departments in other universities.
\end{abstract}

\section{Introduction}

The Greenwich Maths Arcade (formerly known as the Maths Café) began in September 2010 with a grant from the university's Dragons' Den fund. The idea was to run a weekly drop-in session that would enable struggling students to obtain help from staff on tutorial questions whilst at the same time provide a range of puzzles and activities that would stretch the more able students (Bradshaw, 2011, 26).

The motivation stemmed from reading the proceedings of a conference on mathematical support and in particular the keynote address by Celia Hoyles (Hoyles, 2010,4). Hoyles acknowledges the varying backgrounds and confidence of students entering university to read quantitative subjects but insists that it is the university's responsibility to provide the necessary support. At the other end of the spectrum, John Mason et al's., well-known book Thinking Mathematically (Mason, 2010) - which one of the authors reviewed for MSOR Connections (Bradshaw, 2010, 49), suggested that there was much more we could be providing to stretch and motivate our exceptionally able students.

We were aware of Maths Cafés in other universities - particularly Portsmouth (Pevy, 2008) but these exist primarily to provide mathematics support for other disciplines rather than for mathematics undergraduates. We had neither the personnel nor the space to make this a viable option.

\section{Attendance}

One of the concerns of the Dragons' Den panel was whether students would participate. Our view at the time was that there was no guarantee that students would attend but we thought it worth a try. The panel, though slightly sceptical, agreed; influenced perhaps by the enthusiasm and dramatic skills of the two student co-presenters of the bid.

However, last year attendance was never a problem. Timetabling was carefully arranged to be convenient for all mathematics undergraduates. The sessions were linked at the start to the mentoring scheme so mentors arranged to meet the new students at the Maths Arcade. Considering that we did not have much space, the 
average of $25-30$ students a week (20\% of the first year cohort) seemed a suitable number and it was often hard to find adequate space to set up a game. As we had hoped, some attended every week whilst others came sporadically.

\section{Tutorial support}

Some of the students who attended regularly came purely to work on the week's tutorial questions and to ask for help when necessary. They did not usually want to join in with the games but were grateful that staff were on hand to help and explain things when they were stuck.

It was obvious from the start that we were getting students coming to this who would not have wished to identify themselves as needing help by going to a tutor's office but who were happy to turn up, start work and then casually ask questions without it looking as if they were struggling. Other students would migrate to the help sessions after having played some of the games, or would come to listen when they realised a mathematical topic was being discussed.

\section{Strategy games}

Others were motivated primarily by the games. They either tried different ones each week or played the same one again and again, examining the different possibilities and strategies. For example what difference does it make who starts, is it better to play defensively or to attack; when should one play safe and when is it desirable to take risks? Unlike chess clubs which tend to be competitive, the students were keen to discuss strategies and tactics, which has undoubtedly helped them improve their mathematical thinking.

What was particularly pleasing was the diversity of the students who attended. Other events put on either by the department or the university's Maths Society have tended to attract students from a certain sort of background. This however attracted students of different ages, abilities, social groups and mathematical background. It was a very successful way of encouraging the students to get to know each other across a whole year group and boosted the group spirit and morale of the cohort.

It can be particularly hard for maths students, who are often shy, to start conversations and make friends but over a game (or any focussed activity) this becomes much easier. Staff would begin playing games with a small group of students and then move on to another group, leaving the students to continue playing and get to know each other better. This appeared to work, and during the year friendship groups emerged around the games.

The students also liked the fact that lecturers joined in and more importantly that they could beat them at various games. One of the most memorable sessions was when a member of staff played 'Quoridor' with three students. Rather than everyone trying to outwit the other three opponents it became obvious that the students were working in collaboration so that the lecturer would not win. It was great fun, the students did not seem to realise that the lecturer did not come out too badly as it took three of them to beat her!

\section{Which games?}

There are a number of quite unusual board games on the market which have mathematical interest. Games were chosen on the strategic thinking involved. One of the students' favourites so far is 'Quarto' which contains playing pieces with four different attributes:

Size - tall and short

Colour - light and dark

Fill - hollow and solid

Shape - round and square 
The aim is to be the player to complete a row of four containing the same attribute, for example four tall pieces regardless of colour, shape etc. It is natural to think of this game in terms of the mathematical idea of binary representation. What makes this game harder is that you do not choose which piece to play but your opponent chooses your piece for you. So a winning strategy might be to try to engineer a situation where your opponent is only left with pieces that give you a win. This is easier said than done as it is hard to keep track of all the different possibilities that might produce a win. No two games are the same and there are numerous ways that the students can investigate attacking and defensive strategies.

\section{Student and staff feedback}

As part of students' personal development planning, first year students were asked to write about a maths event in which they had participated. About two thirds of the cohort chose to write about the Maths Arcade. The only negative comments received were that one hour was not enough and that the timing might be better for some if it occurred after lectures had finished for the day. These have both been acted on for this year. Positive comments included:

"I like to go to the Maths Arcade because all of my tutors attend it."

"The people who were once strangers to me when I first started (attending the Maths Arcade) are now some of my closest friends."

"I felt somewhat dubious about the word 'enjoyable' being used but I'm glad to say I was quickly proved wrong."

"(It is) a really good way to meet people and get to know the lecturers in a more informal environment."

"Attending Maths Arcade has been a major help for me this year and a huge factor in me having such successful and enjoyable studies."

Initially we had focussed on the benefits to students and had not thought of the benefits to tutors. However the staff attending have found these sessions particularly valuable as they have enabled us to get to know the students in an informal setting. This was something that the students appreciated too. Indeed a recent report by the HEA (Trowler and Trowler, 2010, 8) says that, "interacting with staff has been shown to have

a powerful impact on learning, especially when it takes place outside of the classroom and responds to individual student needs."

\section{Evaluation}

The most rewarding aspect of the Maths Arcade has been seeing our retention, attainment and progression rates, though always good, increase noticeably last year. The pass rate in two first year courses increased from just over $70 \%$ in $2009-10$ to nearly $90 \%$ and the drop-out rate was reduced by almost three-quarters. This is something that was appreciated by department and university senior management. Of course there are many other contributing factors but it is believed that the Maths Arcade played a substantial part in this increase.

\section{National HE STEM Programme support}

Partway through last year the Maths Arcade obtained support from the National HE STEM Programme to extend and increase the provision. This has allowed us to run staff training sessions, purchase more games

and extend our opening times to three hours per week instead of one. This support has also enabled us to share our positive experiences with the university's School of Engineering. 


\section{Impact}

In May 2011 the concept of a Maths Arcade was presented at the Higher Education Academy (HEA) mathematics subject centres Ideas Exchange in Birmingham (HEA Maths, Stats \& OR Network, 2010) and at a seminar organised by the south west spoke of National HE STEM Programme (HE STEM, 2011). As a result of these presentations HE STEM funding has been provided to enable other universities to set up their own Maths Arcades to further this good practice. Currently these are situated in Leicester, Keele, Salford, Bath, Manchester and Sheffield-Hallam with another similar venture based on our idea in Nottingham. Training sessions and follow-up support for these Arcades will be provided by us, also funded by the HE STEM programme.

Another impact was as a result of the presentation at the 2011 University of Greenwich Learning and Teaching conference. A number of staff from across the university came to the presentation and subsequently two similar sessions have been set up in different departments in the Business School by Bernadette Ryan and Julia Mundy.

\section{Conclusions}

This idea came about because of a perceived need to simultaneously stretch and support maths students. It involved trying something new and untested which some colleagues felt was risky. Over the last twelve months we have adapted our provision in regard to student feedback and have had to make changes due to University and other constraints. This project has succeeded in ways that had not been foreseen and appears to have made a real difference to student engagement, retention and achievement, which demonstrates the value of trying speculative ideas. We would encourage others to try similar experiments. The outcome may not be what was originally expected but surprising benefits may ensue.

\section{References}

Bradshaw, N. (2010) Thinking Mathematically (book review). MSOR Connections, 10 (3), p. 49.

Bradshaw, N. (2011) The University of Greenwich Maths Arcade. MSOR Connections, 11 (3), p. 26.

HE STEM. 2011. Transition \& Induction Experiences of WP Students. [Online]. Available at: www.hestem-sw. org.uk/widening-participation/wp-projects/?p=9\&pp=1064 [Accessed 30 October 2011].

HEA MSOR Network. 2010. Ideas Exchange: HE Mathematics Curriculum Innovation. [Online]. Available at: $<$ mathstore.ac.uk/node/1746> [Accessed 30 October 2011].

Hewson, P. (2011) Preliminary Analysis of the National Student Survey. MSOR Connections, 11 (1), pp. 2528.

Hoyles, C. 2010. Mathematics and the Transition from School to University. Responding to the Mathematics Problem: The Implementation of Institutional Support Mechanisms, p. 4. [Online]. Available at: www. mathcentre.ac.uk/resources/uploaded/mathssupportvolumefinal.pdf [Accessed 30 October 2011].

Mason, J. et al. (2010) Thinking Mathematically. $2^{\text {nd }}$ ed. London: Pearson Education. 
Pevy, L. 2008. The Portsmouth University Maths Café-Making a Virtue of Necessity. [Online]. Available at: www.port.ac.uk/departments/academic/maths/mathscafe/information/filetodownload,97161,en.pdf [Accessed 30 October 2011].

Trowler, V., and Trowler, P. (2010) Student Engagement Evidence Summary. York: Higher Education Academy 